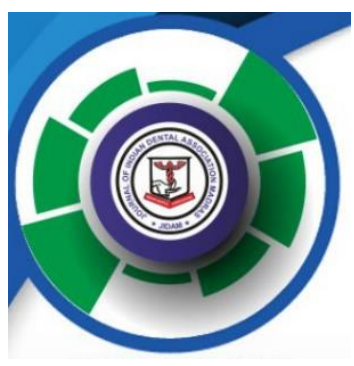

REVIEW ARTICLE

\title{
PULP REVASCULARISATION OF NECROTIC IMMATURE PERMANENT TEETH: A REVIEW
}

Dr Madiha Khan, Dr Ankur Jain, Dr Satish Maran, Dr Rinky Sisodia, Dr Anaya Kulkarni, Dr Sapna Mishra

Department of Pediatric and Preventive Dentistry, Peoples Dental Academy, Bhopal, Madhya Pradesh, India

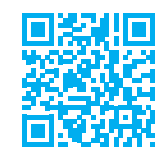

DOI:10.37841/jidam_2021_V8_I1_05

Address for Correspondence:

Dr. Madiha Khan, Post Graduate Student,

143 Rajeev Nagar Kohefiza,

Bhopal, Madhya Pradesh, India

E-mail id: drmadihakhan02@gmail.com

Received: 30.10.2020

First Published: 29.01.2021

Accepted: 08.01.2021

Published: 27.03.2021

\section{ABSTRACT}

As the importance attributed to conservative endodontic treatment increases manifold, pulp revascularization represents a recent and promising therapy for immature teeth, highly recommended as an alternative to apexification in cases of endodontic treatment of irreversible pulpitis and pulp necrosis, whether or not associated with periapical lesion. This review is an attempt towards the recommendation of revascularization as an alternative to apexification.

KEYWORDS: Revascularization, Apexification, Regenerative endodontics, SCAP, Triple antibiotic paste 
Madiha et al: Pulp revascularisation of necrotic immature permanent teeth

\section{INTRODUCTION}

Teeth with incomplete root formation affected by pulp necrosis and periapical periodontitis is conventionally treated with long-term application of calcium hydroxide or the use of mineral trioxide aggregate (MTA), which aim to induce apexification. ${ }^{1}$ The American Association of Endodontists (AAE) has defined this therapy as "a method to induce a calcified barrier in a root with an open apex or the continued apical development of an incompletely formed root in teeth with necrotic pulp". ${ }^{2}$ Despite the fact that this procedure stimulates apical barrier formation, the teeth are more vulnerable to root fractures due to the thin dentin walls. ${ }^{3}$

Regenerative endodontic procedures in recent years have emerged as a favourable alternative to apexification, due in particular to advantages like root development and reinforcement - which prevents fracture of root by increasing length of the root and the dentin wall thickness. ${ }^{4}$ Nonvital infected teeth may be treated with regenerative endodontic procedure in two ways: (1) using tissue engineering technology, which is characterized by the active regeneration of the dentin-pulp complex in order to implant or regenerate the pulp and (2) pulp revascularization, a procedure "in which a new tissue is expected to be formed from the tissue present in the teeth, allowing for the continuation of the development of the root."

Revascularization may be defined as the invagination of undifferentiated periodontal cells from the apical region in immature teeth. ${ }^{6}$ Revascularization, as such, is not new. Ostby ${ }^{7}$ in 1961 introduced revascularization, and in 1966, Rule and Winter ${ }^{8}$ reported development of root and apical barrier formation in cases of pulpal necrosis in children. In 1972, Ham et $\mathrm{al}^{9}$ demonstrated closure of apex of immature pulpless teeth in monkeys. In 2001, Iwaya et $\mathrm{al}^{10}$ and in 2004, Banchs and Trope ${ }^{11}$ demonstrated the advantages of this treatment modality, which resulted in a radiographically apparent normal maturation of the entire root.

In clinical application, pulp revascularization of immature teeth is a type of cell homing strategy for pulp regeneration. It is a two-visit therapeutic approach, which has been proposed in clinical practice over the past decade (Thibodeau and Trope, 2007; Wigler et al., 2013). ${ }^{12,13}$

Several case reports have reported revascularization of necrotic root canal systems by disinfection followed by establishing bleeding into the canal system via over instrumentation. ${ }^{14,15}$ The main aspect of these cases is the use of intracanal irrigants (sodium hypochlorite and chlorhexidine) with placement of triple antibiotic paste (e.g. a mixture of ciprofloxacin, metronidazole, and minocycline paste) for several weeks. This particular combination of antibiotics effectively disinfects root canal systems ${ }^{16,17,18}$ and increases revascularization of avulsed and necrotic teeth ${ }^{19,20}$, suggesting that this is a paramount step in revascularization. An additional research is worthy for the selection of various irrigants and medicaments, because these materials may present with several important effects for regeneration in addition to their antimicrobial properties. For example, the growth of host cells on dentin is enhanced by tetracycline, not by antimicrobial action, but by the exposure of embedded collagen fibres or growth factors. $^{21}$ However, it is not yet known if minocycline shares this effect and whether these additional properties might contribute to successful revascularization.

Although these case reports are largely from teeth with incomplete apical closures, it has been accounted that reimplantation of avulsed tooth with an apical opening of approximately $1.1 \mathrm{~mm}$ has increased chances of revascularization. $^{22}$ This finding suggests that revascularization of fully formed (closed) apices with necrotic pulps may require instrumentation of the tooth apex to approximately 1 to $2 \mathrm{~mm}$ in apical diameter to allow systemic bleeding into root canal systems. Clearly, the development of regenerative endodontic procedures may require re-examination of many of the closely held precepts of traditional endodontic procedures. The revascularization method assumes that the root canal space has been disinfected and that the formation of a blood clot yields a matrix (e.g., fibrin) that entraps cells proficient of initiating new tissue formation. It is not clear that the regenerated tissue's phenotype resembles dental pulp; however, case reports published to date do demonstrate continued root formation and the restoration of a positive response to thermal pulp testing. ${ }^{14}$ Another important point is that younger adult patients generally have a greater capacity for healing.

\section{MECHANISM OF REVASCULARISATION ${ }^{23}$}

According to Shah N, the possible mechanisms by which the process of revascularization takes place is as follows:

A few vital undifferentiated pulp cells remaining at the apical end of the root canal might proliferate into the newly formed matrix and differentiate into odontoblasts. This may happen under the influence of the cells of Hertwig's epithelial root sheath, which are quite resistant to destruction, even in the presence of inflammation. Atubular dentin is laid down by the odontoblasts at the apical end of the root canal and on lateral aspects of dentinal walls of the root canal. This leads to apexogenesis, reinforcing and strengthening of the root. 
Madiha et al: Pulp revascularisation of necrotic immature permanent teeth

Continued root development could be due to multipotent dental pulp stem cells, which are present in immature permanent teeth. These cells from the apical end might be seeded on to the existing dentinal walls and might differentiate into odontoblasts and deposit tertiary or atubular dentin.

Stem cells in the periodontal ligament can proliferate and grow within the root canal and into the apical end. They may lay down hard tissue both at the apical end and on the lateral root walls. The evidence in support of this hypothesis is presented by documentation of cementum and Sharpey's fibers in the newly formed tissues.

The fourth possible mechanism of root development could be because of SCAP or the bone marrow. Instrumentation beyond the confines of the root canal to induce bleeding can also implant mesenchymal cells from the bone to the canal lumen. These cells have extensive proliferating capacity.

The blood clot is a rich source of growth factors such as platelet-derived growth factor, vascular endothelial growth factor, platelet derived epithelial growth factor and tissue growth factor. These could play a major role in regeneration.

\section{INDICATIONS ${ }^{6}$}

- $\quad$ Teeth with necrotic pulp and immature apex

- Pulp space not needed for post/ core, final restoration

- Patient compliance

- No allergy to the medicaments to be used.

\section{CONTRAINDICATIONS ${ }^{6}$}

- $\quad$ Cysts and tumors

\section{CLINICAL PROTOCOL ${ }^{24}$}

\section{Pulp revascularization using calcium hydroxide} First Appointment Procedure

- Local anaesthesia (Articane with vasoconstrictor (1:200000)

- Isolation of the tooth with a rubber dam

- Opening of the pulp chamber to canal entrance (pulpotomy)

- Irrigation of root canal (often with $10 \mathrm{ml}$ sodium hypochlorite at $2.5 \%$ )

No instrumentation in root canal

- Preparation of calcium hydroxide paste.
- Insertion of the paste in the pulp chamber and in the coronary part (third or half) of root canal (with a cotton ball).

- Sealing of the access cavity with a temporary filling.

Second Appointment Procedure

(two or three weeks later if asymptomatic tooth and/or absence of fistula)

- Local anaesthesia without vasoconstrictor (in order to not inhibit the future apical bleeding.)

- Isolation of the tooth with a rubber dam

- Opening the tooth to have a access to root canal

- Removal of the calcium hydroxide paste

- Copious irrigation of root canal with sodium hypochlorite

- Rinsing root canal with sterile water

- Drying root canal with paper cones

- An apical bleeding is caused by irritation of the apical region with a $15 \mathrm{~K}$-file lime (It takes 15 minutes to obtain a blood clot. If a root canal is not bleeding, it is possible to transfer blood from one root canal to another. Blood level must be at least 2-3 mm below the cementoenamel junction.)

- $\quad$ Preparation of mineral trioxide aggregate (MTA) was done according to manufacturer's instructions at a powder-to-liquid ratio of 3:1, an MTA carrier is used to carry the material incrementally into the root canal; the material was packed with the use of hand plugger up to the proper length on the clot in order to form a hermetic sealing. ${ }^{25}$

- Place a wet a cotton ball on MTA filling

- Sealing of the cavity with a temporary filling

Calcium hydroxide and its capacity to induce hard tissues in immature teeth with pulp necrosis

A substantial amount of research exists on the effect of calcium hydroxide on apical healing events after pulp necrosis in young teeth with immature roots. ${ }^{26}$ The essential features appear to be, as in the coronal use of calcium hydroxide, a bacteria killing effect as well as a hard tissue inducing effect, the later related to the initiation of zones of liquefaction and coagulation necrosis next to the apical vital tissue. This results in the development of hard tissue at the apex (apexification), usually as a cementum-like structure. ${ }^{27}$ The drawback of this hard tissue bridge is that numerous vascular channels, which could lead to bacterial invasion into these channels and perforate it. ${ }^{26}$

Mineral trioxide aggregate and its capacity to induce hard tissues in immature teeth with pulp necrosis 
Madiha et al: Pulp revascularisation of necrotic immature permanent teeth

MTA has shown to be a very biocompatible material, infact more biocompatible than Super EBA and IRM. ${ }^{28}$ The successful use of this material in immature teeth with pulp necrosis is possibly related to two features:

1.The extraordinary cementum and PDL-inducing potential of MTA.

2.The bacteria tight sealing capacity of MTA when placed in the apical part of the root canal.

This combination of a bacteria tight seal in the apical foramen of the root canal and formation of new cementum and PDL makes this technique a very biologically acceptable method for closing a root canal with an open apex. ${ }^{29}$ In a recent review article, on the mechanism of action of MTA on pulpal and periodontal tissues, the following actions are described: when placed, MTA immediately releases calcium ions activating cell attachment and proliferation, and at the same time, the high $\mathrm{pH}$ creates an antibacterial environment. Furthermore, MTA modulates cytokine production and encourages differentiation and migration of hard tissue producing cells whereby hydroxyapatite is formed on the MTA surface, and a biologic seal is created. ${ }^{30}$

When MTA is used as an apical plug in cases of pulp necrosis, studies in dogs and monkeys where apical osteitis was induced showed that MTA can form a biologic seal and the MTA becomes covered with cementum and a normal PDL attachment. ${ }^{31}$ Several studies have shown that when used as a root-end filling material MTA demonstrates a good resistance to bacterial penetration as well as to endotoxin. ${ }^{32}$

Pulp revascularization using a triple antibiotic paste (TAP). ${ }^{24}$

First step

- Local anaesthesia was administered.

- Isolation of the tooth with a rubber dam.

- Disinfection of the tooth with $10 \%$ povidone-iodine (iso-Betadine) before opening it.

- Opening of the pulp chamber to canal entrance (pulpotomy).

- Irrigation of root canal with $20 \mathrm{~mL}$ sodium hypochlorite $(1.25 \%-5.25 \%)$ then with physiological serum and finally with $2 \%$ chlorhexidine.

- No instrumentation in root canal.

- Drying root canal with paper cones. Insertion of the triple antibiotic paste into root canal (Mixture of equal proportion of three antibiotics: metronidazole, ciprofloxacin, and minocycline bonded with propylene glycol. Minocycline may be replaced by cefaclor to avoid inducing coloration)

- Place a cotton ball at the root canal entrance.

- Sealing of the access cavity with a temporary filling.

\section{Second step (two or three weeks later if} asymptomatic tooth and/or absence of fistula)

- Local anaesthesia without vasoconstrictor.

- Isolation of the tooth with a rubber dam.

- Disinfection of the tooth with $10 \%$ povidone-iodine (iso-Betadine) before opening it.

- Opening the tooth to have a access to root canal.

- Removal of the triple antibiotic paste using irrigation with sodium hypochlorite $(1.25 \%-5.25 \%)$ then with physiological serum and finally with $2 \%$ chlorhexidine.

- An apical bleeding is caused. Blood level must be at the cementoenamel junction.

- $\quad$ Preparation of mineral trioxide aggregate (MTA) was done according to manufacturer's instructions at a powder-to-liquid ratio of 3:1, an MTA carrier is used to carry the material incrementally into the root canal; the material was packed with the use of hand plugger upto the proper length on the clot in order to form a hermetic sealing. ${ }^{25}$

- $\quad$ Place a wet a cotton ball on MTA filling Sealing of the cavity with a temporary filling

According to Chen et al. ${ }^{33}$ immature teeth diagnosed with pulp necrosis and apical periodontitis may present four types of revascularization outcome:

Type I- increased dentin wall width and root-end development.

Type II- insignificant continued root development associated with apical closure.

Type III- root-end development without apical closure;

Type IV-calcification (obliteration) of root canal;

Type V- mineralized tissue barrier between MTA cervical plug and radicular apex

\section{ADVANTAGES ${ }^{34}$}

There are several advantages to a revascularization approach.

- The approach is technically simple and can be completed using currently available instruments and medicaments without expensive biotechnology.

- The regeneration of tissue in root canal systems by patient's own blood cells avoids the possibility of 
Madiha et al: Pulp revascularisation of necrotic immature permanent teeth

immune rejection and pathogen transmission from replacing the pulp with a tissue engineered construct.

- Short treatment time.

- $\quad$ Cost effective.

- Obturation of canals not required.

- Continued root development and strengthening.

\section{LIMITATIONS ${ }^{35}$}

However, there are several concerns that need to be addressed in future research. Primarily, the case reports of a blood clot having the capacity to regenerate pulp tissue are exciting, but caution is required, because the source of the regenerated tissue has not been identified. Furthermore animal studies and clinical studies are required to investigate the potential of this technique before it can be recommended for general use in patients. Generally, tissue engineering does not rely on blood clot formation, because the concentration and composition of cells trapped in the fibrin clot is unpredictable. This is a critical limitation to a blood clot revascularization approach, because tissue engineering is based on the delivery of effective concentrations and compositions of cells to restore function. It is very much possible that variations in cell concentration and composition, particularly in older patients (where circulating stem cell concentrations may be lower) may lead to variations in treatment outcome.

On the other hand, some aspects of this approach may be useful; plasma-derived fibrin clots are being used for development as scaffolds in several studies. Second, enlargement of the apical foramen is necessary to promote vascularizaton and to maintain initial cell viability via nutrient diffusion. Related to this point, cells must have an available supply of oxygen; therefore, it is likely that cells in the coronal portion of the root canal system either would not survive or would survive under hypoxic conditions before angiogenesis. Interestingly, endothelial cells release soluble factors under hypoxic conditions that promote cell survival and angiogenesis, whereas other cell types demonstrate similar responses to low oxygen availability. Other limitations like crown discolouration, development of resistant bacterial strains, allergic reactions to intracanal medications and calcification of the canal may also arise.

\section{CONCLUSION}

Induced generation and regeneration of vital tissues in the pulp space can thicken the root structure leading to a stronger tooth with a potentially reduced fracture risk. Apexification procedure may no longer be the preferred first option to treat immature permanent teeth with nonvital pulps. Revascularization represents a recent and promising treatment modality that has been in evidence due to the preservation of biological principles and the possibility of minimizing the treatment period of immature teeth.

\section{FINANCIAL SUPPORT AND SPONSORSHIP}

Nil

\section{CONFLICTS OF INTEREST}

There are no conflicts of interest.

\section{REFERENCES}

1. Thibodeau B, Trope M. Pulp revascularization of a necrotic infected immature permanent tooth: case report and review of the literature. Pediatr Dent 2007;29(1): 47-50.

2. American Association of Endodontists. Glossary of Endodontic Terms. 9th ed. Chicago, Ill., USA: American Association of Endodontists; 2016:5.

3. Rafter M. Apexification: a review. Dent Traumatol 2005; 21(1):1-8.

4. Narang I, Mittal N, Mishra N. A comparative evaluation of the blood clot, platelet-rich plasma, and platelet-rich fibrin in regeneration of necrotic immature permanent teeth: a clinical study. Contemp Clin Dent 2015;6(1):63-8.

5. Bansal R, Bansal R. Regenerative endodontics: a state of the art. Indian J Dent Res 2011;22(1):12231.

6. Garcia-Godoy F, Murray PE. Recommendations for using regenerative endodontic procedures in permanent immature traumatized teeth. Dent Traumatol. 2012; 28(12):33-41.

7. . Ostby BN. The role of blood clot in endodontic therapy: An experimental histologic study. Acta Odontol Scand. 1961; 19:324-353.

8. Rule DC, Winter GB. Root growth and apical repair subsequent to pulpal necrosis in children. Br Dent J. 1966; 120:586-590.

9. Ham JW, Patterson WW, Mitchell DF. Induced apical closure of immature pulpless teeth in monkeys. Oral Surg Oral Med Oral Pathol. 1972, 33.

10. Iwaya S, Ikawa M. Revascularization of a tooth with apical periodontitis and a sinus tract Dent Traumatol, 2001; 17:185-187.

11. Banchs F, Trope M. Revascularization of immature permanent teeth with apical periodontitis: New treatment protocol? J Endod. 2004; 30:196-200.

12. Thibodeau, B., and Trope, M. Pulp revascularization of a necrotic infected immature permanent tooth: case report and review of the literature. Pediatr. Dent.2007; 29: 47-50. 
Madiha et al: Pulp revascularisation of necrotic immature permanent teeth

13. Wigler, R., Kaufman, A. Y., Lin, S., Steinbock, N., Hazan-Molina, H., and Torneck, C. D. Revascularization: a treatment for permanent teeth with necrotic pulp and incomplete root development. J. Endod2013;39:319-326.

14. Thibodeau B, Teixeira F, Yamauchi M, et al. Pulp revascularization of immature dog teeth with apical periodontitis. J Endod 2007;33:680-9.

15. Wang X, Thibodeau B, Trope M, et al. Histologic characterization of regenerated tissues in canal space after the revitalization/revascularization procedure of immature dog teeth with apical periodontitis. J Endod 2010;36:56-63.

16. Sato I, Ando-Kurihara N, Kota K, Iwaku M, Hoshino E. Sterilization of infected root-canal dentine by topical application of a mixture of ciprofloxacin, metronidazole and minocycline in situ. Int Endod J 1996;29:118 -24.

17. Hoshino E, Kurihara-Ando N, Sato I, et al. In-vitro antibacterial susceptibility of bacteria taken from infected root dentine to a mixture of ciprofloxacin, metronidazole and minocycline. Int Endod $\mathbf{J}$ 1996;29:125-30.

18. Sato T, Hoshino E, Uematsu H, Noda T. In vitro antimicrobial susceptibility to combinations of drugs on bacteria from carious and endodontic lesions of human deciduous teeth. Oral Microbiol Immunol 1993;8:172-6.

19. Ritter AL, Ritter AV, Murrah V, Sigurdsson A. Trope $M$ pulp revascularization of replanted immature dog teeth after treatment with minocycline and doxycycline assessed by laser Doppler flowmetry, radiography, and histology. Dent Traumatol 2004;20:75-84.

20. Yanpiset K, Trope M. Pulp revascularization of replanted immature dog teeth after different treatment methods. Endod Dent Traumatol 2000;16:211-7.

21. Terranova VP, Odziemiec C, Tweden KS, Spadone DP. Repopulation of dentin surfaces by periodontal ligament cells and endothelial cells effect of basic fibroblast growth factor. J Periodontol 1989;60:293-301.

22. Kling M, Cvek M, Mejare I. Rate and predictability of pulp revascularization in therapeutically reimplanted permanent incisors. Endod Dent Traumatol 1986;2:83-9.

23. Rohit Pannu. Pulp revascularisation - An evolving concept: A review. International Journal of Applied Dental Sciences 2017; 3(4): 118-121

24. Mélanie Namour, Stephanie Theys. Pulp Revascularization of Immature Permanent Teeth: A Review of the Literature and a Proposal of a New
Clinical Protocol. The Scientific World Journal 2014:1-9

25. Ghasemi N, Janani M, Razi $\mathrm{T}$ and Atharmoghaddam F. Effect of different mixing and placement method on the quality of MTA plug in stimulated apexification model. J Clin Exp Dent 2017:9(3);351-355

26. Cvek M, Sundström B. Treatment of non-vital permanent incisors with calcium hydroxide. V. Histologic appearance of roentgenographically demonstrable apical closure of immature roots. Odontol Revy 1974; 25: 379-92.

27. Binnie WH, Rowe AHR. A histological study of the periapical tissues of incompletely formed pulpless teeth filled with calcium hydroxide. J Dent Res 1973; 52: 1110-6.

28. Fernández-Yáñez Sánchez A, Leco-Berrocal MI, Martínes-González JM. Metaanalysis of filler materials in periapical surgery. Med Oral Patol Oral Cir Bucal 2008; 13: 180- 5.

29. Bakland LK. New procedures using mineral trioxide aggregate (MTA) for teeth with traumatic injuries. In: JO Andreasen, FM Andreasen, L Andersson, editors. Textbook and color atlas of traumatic injuries to the teeth, 4th edn. Oxford: Blackwell; 2007. p. 658-68.

30. Parirokh M, Torabinejad M. Mineral trioxide aggregate: a comprehensive literature review-part I: chemical, physical, and antibacterial properties. $J$ Endod 2010; 36: 16- 27.

31. Felippe WT, Felippe MCS, Rocha MJC. The effect of mineral trioxide aggregate on the apexification and periapical healing of teeth with incomplete root formation. Int J Endod 2006; 39: 2-9.

32. Tang HM, Torabinejad M, Kettering JD. Leakage evaluation of root end filling materials using endotoxin. J Endod 2002; 28: 5- 7.

33. Chen MY, Chen KL, Chen CA, Tayebaty F, Rosenberg PA, Lin LM. Responses of immature permanent teeth with infected necrotic pulp tissue and apical periodontitis/abscess to revascularization procedures. Int Endod J. 2012; 45(2):294-305

34. do Couto AM, Espaladori MC, Leite APP, Martins CC, de Aguiar MCF, Abreu LG. A Systematic Review of Pulp Revascularization Using a Triple Antibiotic Paste. Pediatr Dent 2019;41(5):341-53.

35. Yang J, Yuan G and Chen Z . Pulp Regeneration: Current Approaches and Future Challenges. Front. Physiol 2016;7:1-8. 